\title{
Research on Construction of NC Technology Practice Teaching Base Xiaoling Wei ${ }^{1, a}$, Mingsheng Song ${ }^{1, b^{*}}$ and Yu Jiang ${ }^{1, c}$ \\ ${ }^{1}$ Hebei University of engineering, College of Mechanical and Equipment Engineering, Hebei Handan, China, 056038 \\ awxlcsm@163.com, b451596296@qq.com, ${ }^{\mathrm{a}} 729197276 @ q q . c o m$ \\ *The corresponding author
}

Keywords: NC technology; Practice teaching base; Personnel training; Machinery manufacturing

\begin{abstract}
Regarding to the currently developing tendency of the numerical control technology and the urgent demand of the manufacturing industry to the people who possess professional knowledge, hence this paper indicates the importance of strengthening the construction of NC technology practice teaching base. This thesis notes concrete methods combined the experience of construction of NC technology practice teaching base. The foundation has become a base which cultivates innovation ability and practical teaching of students of mechanical manufacturing in our school. It outputs plenty of outstanding personnel with enough technologies for the society.
\end{abstract}

\section{Introduction}

Numerical control (NC) technology and high-end equipment manufacturing capacity is very important for the security and economic prosperity of a country in the current world situation, reflecting comprehensive national strength and technical level of a country. Over the past 10 years, manufacturing industry of China has formed a certain scale [1].China is a veritable big country in manufacturing industry now, but still not powerful enough in manufacturing. Aiming at being a powerful manufacturing country in a true sense, it is necessary to speed up the development of NC technology of China, promoting transformation and upgrading of manufacturing enterprises and industrial adjustment. Cultivating a large number of personnel who master the advanced manufacturing of new technologies, new methods and could adapt to the requirements of new manufacturing areas. They are also involving high-quality technical skills in mechanical and professional technology. Practice teaching base plays an irreplaceable role in better grasping the NC technology for students. Our NC technology practice teaching base was established in June, 2004, which was formed by the NC technology laboratory, special processing laboratory, plastic molding and mold manufacturing laboratory. It is an important place of mechanical students in training, teaching and conducting experiments. After several years of programming, construction and development, in June 2010, Handan City, the key laboratory of modern manufacturing technology was set up finally. Its practice teaching base hardware and software conditions have been greatly improved and formed a certain scale now. In order to adapt to requirements of machinery professional personnel of the development of manufacturing industry, combined with the industry "12th Five-Year" development planning and construction of Handan city "Chengfeng equipment manufacturing industrial town" spirit of high-end equipment manufacturing, it is of great significance to accelerate the construction of NC technology practice teaching base.

\section{The Importance of Numerical Control Technology to the Personnel Cultivation of Mechanical Manufacturing Specialty}

$\mathrm{NC}$ technology is based on the traditional manufacturing technology, integrating mechanical engineering, electronics, automation technology, information technology and other technology. It is utilized in all areas of manufacturing to achieve goals in high quality, high efficiency, low consumption, clean and flexible production [2] on the basis of absorbing a variety of high-tech achievements. NC technology is the carrier of high-tech manufacturing industry. It is the strategic emerging industries of leading the manufacturing industry, core technology and equipment. It has 
aroused great concerns of many countries as the global manufacturing industry in seizing the market. In the complex and changeable situation of the current international situation, the developed countries led by the United States make re-understanding and positioning on the manufacturing industry around the world, a series of measures were taken to study the strategy of manufacturing industry in twenty-first Century. At the same time a series of implementation plan to promote the development of NC technology were put forward .China manufacturing industry "12th Five-Year" development plan also clearly stated that manufacturing and high-end equipment manufacturing industry are the backbone of the modern industrial system and the engine to promote industrial restructuring and upgrading. It is essential to cultivate and develop high-end equipment manufacturing industry to enhance the core competitiveness of China industries. It is also a strategic choice to seize the commanding heights of the future economy and science and technology as well as has an important significance for accelerating the transformation of economic development mode and becoming a powerful manufacturing country. NC technology has provided opportunities and challenges for the development of the manufacturing industry; manufacturing enterprises must scientifically determine and accurately grasp the development trend. Enterprises can survive and the manufacturing industry will achieve the changes by the "Made in China" to "Created in China" only to understand the situation, possess a clear direction, speed up the upgrading of industrial structure transformation, master key components of the core technology and high-end equipment manufacturing sets of technology. Manufacturing and high-end equipment manufacturing industry is the lifeblood of enterprises, the personnel who own the $\mathrm{NC}$ technology is the foundation to achieve the development of manufacturing industry. Without high-quality talents, manufacturing will not enter the rapid development period. Therefore, as a university which aims to the cultivate numerical control technical personnel, the college has to strengthen training in high-level and highquality technical skills of mechanical professional personnel. In the process of talent cultivation, besides paying attention to the forefront of theoretical and systematic teaching, the construction of practical teaching base should be increased. It is accessible to improve their ability to master numerical control technology through a vast amount of engineering practice training. Combining the practical characteristics of our college, the construction of the NC technology practice teaching base should closely focus on the development direction of numerical control technology, and constantly adjust the content and methods of practice teaching. In addition, it is also supposed to strengthen the practice teaching base of hardware and software construction and management level, sustain the great responsibilities of the times. That is of utmost importance to master advanced manufacturing technology talent.

\section{The Concrete Measures of Base Construction of NC Technology Practice Teaching}

To Adapt to the Development of the Times and Speed up the Construction of Practical Teaching Base Hardware. The construction of NC technology practice teaching base in our university always follows the principle of "strengthening foundation, paying attention to quality, cultivating ability and inspiring innovation"[3]. The cultivate goal and thinking of the base is clearly proposed. In order to meet the needs of the market and speed up the transformation and upgrading of manufacturing enterprises in Handan as well as serve the local economic development in 2010, our college put forward the development ideas of modular construction for practice teaching base, emphasizing the role of CAD/CAM technology, virtual manufacturing, simulation technology, optimization analysis and information technology in practice teaching. For meeting the demands of talents of the development of numerical control technology, the construction of the practice teaching base is further planned and a new talent cultivation framework. It put forward: taking the modern educational concept as the guide, mastering the theoretical knowledge as the basis, taking the social demand as the direction, with the aim of talent cultivation, taking engineering training as the means, improving teaching quality as the tenet, cultivating innovation ability as the main line, and improving the overall quality as the core, constructing a new experimental teaching system that adapts to the development of the times. The quantity and quality of the experimental equipment have been highly improved. All kinds of machine tools including NC lathe, milling machine, special 
processing machine tools, $\mathrm{CNC}$ machining centers and $\mathrm{CNC}$ system fault diagnosis platform and other equipment on a hundreds units, more than 10 million yuan worth. Equipment performance is advanced, and it basically meets the requirements of the comprehensive experiments and scientific activities. For the sake of cultivating the ability of mechatronics of mechanical students, in 2013, practice teaching base bought two sets of "four-in-one CNC machine tool control and maintenance of electrical training platform", which make the students master the principle of CNC machine tools, electrical design and components selection methods, machine tool installation and commissioning, fault diagnosis and maintenance, part program preparation and simulation process and other experimental projects. The equipment greatly enriches the content of student training teaching, achieving the goal of working in the industrial production, carrying out special project practice and providing a good platform for students. The next step of the construction of practice teaching base also needs to combine the market with social development. The base should increase the extent of school-enterprise cooperation as well as establishing close cooperation of complementary advantages, equality, mutual benefit and common development between industry and academia. Furthermore it also needs to make up the lack of training equipment and the problem of unitary function. Practice teaching base can employ technical experts and skilled operators to participate in the base construction and practical guidance, so that they can solve the project development and technical problems of the cooperative enterprise under the support of research institutions of university. The priority of scientific research is transferred to the cooperative enterprise. Enterprises can arrange mechanical students who accept to learn and train in the actual site the training during their holiday, to make up for shortcomings of the practice teaching base. In the training of machinery manufacturing students of 2017 " $3+4 "$ secondary vocational undergraduate level, our college will imply the " $3+1 "$ mode that senior students directly go to the cooperative enterprises to initiate one-on-one guidance and internship. The mode can make students master the CNC technology. It greatly improved their hands-on ability and overall quality. In the meantime, university will carry out regular theory training for technical personnel and occasional seminars at enterprises, introducing the current new trends and new problems in the field of advanced manufacturing. This is a cooperation relationship which involves mutual trust and benefit is positive and significant for the construction of the practical teaching base hardware.

To Improve the Management Level and Speed up Network Construction of the Practice Teaching Base. With the development of science and technology, network and open management have become the inevitable trend of the construction of practical teaching base. The management of NC practice teaching base can not only stay in the old-fashioned way, for instance, personally allocating personnel, task arrangement as well as performance demonstration and solving the problem by face to face. Besides the strict management of personnel responsibilities, daily management specification, equipment operation and maintenance system and other management documents with teaching documents, the main task of the base is to improve the quality of practical teaching. The web-construction is an effective mean for the base to improve modern management level and training effect. NC technology practice teaching base should be based on the existing resources, using industrial Ethernet as network platform, combining with the integration of software of CNC machine tools, product design, simulation processing, teaching and training process management, to form a teaching environment with the combination of a full range of network. To achieve the teaching base of network construction and CAD / CAE / CAPP / CAM highly integrated, teachers and students interactive layout, accepting the design tasks and submit design work through the network. Meanwhile, teachers are able to review, check the operation through the network. The entire process is completed all through the network that can both save time and improve efficiency as well as realize a reasonable allocation of existing CNC equipment resources. The network construction of practice teaching base could increase software applications of students in product design, process analysis, simulation, providing students with efficient program editing, modification and simulation processing experimental platform. That will enable students to master the product design and the key technologies in networked digital manufacturing. The network construction of practice teaching base could centralize on managing document management, 
sharing, query and security during process of design and production, publishing new information and new tasks of practice teaching base, issuing the use of equipment resource, the statement of student training program as well as the specific time of reply and report and performance of students project training. At the same time, students can also request to the base through the network to utilize equipment, asking the problems of training. In short, the network construction injects vitality to further develop and improve for the practice teaching base, as well as enhancing the management level and modernization of the base.

To Combined with Personnel Training Objectives and Enrich the Project Content of the Practice. In accordance with the demand for mechanical professionals in the current manufacturing industry and the training objectives of mechanical personnel in colleges, it is necessary to project the function of the base. For this personal idea is: based on the serious study of modern design concepts, design methods, NC technology, automation technology and information technology, we should make a deep excavation of teaching content of the current practice teaching base. At the same time a clear level and rich content of the practical teaching system should be set up to increase the relative integrity of modern integrated manufacturing technology integrated experimental project[5]. On the basis of maintaining the original comprehensive experiment and training contents, the specific project practice and innovative experiment content are added. The specific project practice is based on the comprehensive experiment, and tasks are arranged in the junior year. Students can choose the topic to be trained according to their own interests, and use the knowledge of CAID, PROR / E, RE, CAE and CAM to finish the whole process of design, modeling, process analysis, programming, manufacture and inspection of a electromechanical products, cultivating ability of students to adapt to society and solve practical problems independently. Meanwhile, in conjunction with the implement of the CDIO project, we can establish innovative experimental groups and teams for outstanding students and encourage them to apply for science and technology projects, participating in teacher research projects actively. For the implement of the project in the guidance of teachers of the base, we will establish the effective evaluation and management system of the quality of the project through the combination of project presentation, replying and reporting to test the effectiveness and quality of teaching practice. Instructors give comprehensive performance assessment under the student statement, the content of the respondent, the practice report, the usual attendance, the machine operation level, practice report writing and complete the product quality. To cultivate the talent who master the ability of NC technology application, we need to create a good atmosphere for scientific research, providing innovative research and experimental platform for outstanding students, enhancing their engineering practice and innovation, and cultivating their team awareness and professionalism, improving their scientific literacy.

To Excavate the Internal Potential and Maximize the Effectiveness of Practice Teaching Base. At present, the NC technology practice teaching base of our school, the quantity or quality of the equipment has a certain scale, teachers strength is relatively strong, scientific research activities and scientific and technological innovation activities of students are frequent, the level of management and technology of the whole base has reached a certain height. But there is still a problem in the construction of the base: equipment are idle when there is no experimental teaching task nor open experiments nor research activities between teachers and students. On the one hand, the fund of the base construction relies on the school fees; on the other hand personnel and equipment cannot create benefits, lacking flexible management policies, leading to limit the development of the base. In author's personally view: universities should develop policies to encourage the practice teaching base in the completion of their practice teaching tasks and teachers with students on the basis of scientific research needs, allowing the provision of technical and processing services which can not only make full use of effective resources to create benefits for both university and base, but also could provide a good exercise training for the ability of engineering training for students and increase the visibility of the college. To strengthen the academic exchanges of the base, we could learn good experience and practice from other universities to enhance their level and influence, increasing vocational training and skills identification and other qualifications of the base, establishing skills identification and training 
institutions. Relying on the existing advanced manufacturing equipment and faculty, school is able to train the enterprise engineers and first-line skilled workers and making qualification examination as well as accreditation to the employment personnel of Handan City and the surrounding areas. At the same time we are supposed to establish the scientific research and training program, guiding students to participate in a variety of scientific and technological competitions through lectures, reports and other forms [6-10], organizing students to participate in National Competitive Competence of Engineering Training for College Students. The school should make the development of the base step into a virtuous circle track through improving ability of application and spirit of innovation of NC technology of students in various forms.

\section{Conclusions}

China manufacturing industry must rely on innovation to achieve the transformation from a big manufacturing country to a powerful manufacturing country, the main part of innovation is people, without outstanding personnel involving enough technologies of NC technology, there would be no manufacturing development, improvement of national strength and international competitiveness. Therefore, it is a difficult responsibility for colleges and universities to strengthen the training of high-level and high-quality technical talents. The NC technology practice teaching base is the important base which carries on the numerical control technology practice teaching in the colleges and universities, the important place which fosters the high quality innovation talented person, the theory teaching and the practice unifies the important embodiment, the important guarantee to promote the practice of teaching reform and speed up the cultivation of NC technology. Building up $\mathrm{NC}$ technology practice teaching base, strengthening quality supervision and control of the quality of training teaching, achieving the dynamic management of teaching practice and constantly adjusting the construction ideas and development direction of the base. Based on servicing locality and building competitive products, the school will further improve the mechanical professionals to master the ability of $\mathrm{NC}$ technology. That is of great significance for Handan City and even the development of China manufacturing industry.

\section{Acknowledgements}

The Research and Practice Project of Hebei Higher Education Reform in 2016(Number: 2016GJJG125).

\section{Reference}

[1] J.J. Wang, G.S. Fang and T.L. Wang: Education for Chinese After-school(Theory), (2012) No. 5. p. 21-22, (In Chinese).

[2] X.B. Li: Public Communication of Science \& Technology, (2012) No. 8. p. 166-167, (In Chinese).

[3] Y. Zhang and L. Ling: Continue Education Research, (2014) No. 4. p. 121-123, (In Chinese).

[4] G.D. Ren, F.Z. Dai and X. Wang: China Electric Power Education, (2011) No. 11. p. 141-145, (In Chinese).

[5] J.L. Liu and R. Hu: Experiment Science and Technology, Vol 9 (2011) No. 2. p. 136-137, (In Chinese).

[6] Z.P. Ren: Chinese Vocational and Technical Education, (2010) No. 2. p. 89-90, (In Chinese).

[7] J. Mi: China Electric Power Education, (2011) No. 25. p. 148-149, (In Chinese).

[8] X.L. Wei, B.G. Zhang and J.F. Wang: Journal of Hebei University of Engineering(Social Science Edition), Vol 31 (2014) No. 2. p. 80-82, (In Chinese). 
[9] L. Zhang, C.H. Huang and W.J. Wu: China Electric Power Education, (2013) No. 32. p. 170171, (In Chinese).

[10] C.R. Yang: Journal of Wuhan Technical College of Communications, Vol 17 (2015) No. 4. p. 39-41, (In Chinese). 